\title{
Evaluation and Analysis of Tractor Driver's Seat Vibrations without Implements and with Implements during Tillage Process
}

\author{
Harbhinder Singh ${ }^{1}$, Munish Mehta ${ }^{2}$ \\ I*Research Scholar, School of Mechanical Engineering, Lovely Professional University, \\ Phagwara, \\ ${ }^{2}$ School of Mechanical Engineering, Lovely Professional University, Phagwara, India \\ *Corresponding Author email: harry2211@ rediffmail.com
}

\begin{abstract}
-
In day to day operations tractor has to move with tillage implements and without tillage implements. In this work emphasis has been given to compare the effect of vibrations on driver's seat of tractor while working with implements during tillage and while working without implements. The experiment was conducted in the fields of Punjab (India). During the experiment, first time the tractor was made to move without implements and second time tractor was moving with chisel plough (tillage implement). Both times real time vibration data of driver's seat was collected with three-axis accelerometer and it was observed that when tractor was moving without implements the vibration amplitude was highest in vertical direction $Z$ as compared to transverse direction $Y$ and horizontal direction $X$. But when the tractor was moving in the fields with tillage implement (chisel plough) the vibration amplitude was high in transverse direction $Y$ relative to horizontal direction $X$ and vertical direction $Z$.
\end{abstract}

Key Words - Tractor, vibration, tillage implements, accelerometer.

*Author for Correspondence

\section{INTRODUCTION}

Tractors are used worldwide as agriculture tools. As tractors have to work on rough surfaces specifically during tillage so high amplitude vibrations travel to the operators seat. These vibrations are harmful to the operators and drivers feel uncomfortable with unwanted vibrations. Mechanical structures may also fail due to vibrations and reduce performance of equipment and machinery. Therefore, it becomes necessary to reduce the vibrations to compensate the undesirable vibration effects in tractors.

Only tires give flexibility and absorb some vibrations. That's why vibrations in tractors are of high amplitude [1, 2 and 3]. The road surface is the major factor for vibrations in the tractors. Effect of vibrations on human body depends upon magnitude, frequency and direction of vibrations [4]. During soil tillage operations higher vibration levels are 
transmitted to the human body [5, 6 and 7]. The high level vibrations are very harmful to operator and may cause deafness and disorders of the spinal column and stomach. Such high level vibrations are due to inadequate conditions such as surface roughness, high forward speed, faulty tillage equipments etc. [8,9 and 10].Forward speed of tractor during tillage is very important component and due to this component vibration levels increase by $40 \%$ if the speed is increased by less than $4 \mathrm{Km} / \mathrm{hr}$ [11].

\section{MATERIALS AND METHODS}

The real time data was collected from the tractor seat. The experiment was conducted for two different conditions. First time data was taken from tractor seat when the tractor was moving without implements and in second case experimental vibrational data was collected from tractor seat when tractor was working in the fields with chisel plough during tillage.

During both cases vibrations were measured with tri-axial piezoelectric accelerometer. The accelerometer was installed on the contact point at seat base. A setup was made for the measuring vibration in $\mathrm{X}, \mathrm{Y}$ and $\mathrm{Z}$ direction. The vibration measuring accelerometer was capable to quantify the instantaneous vibration of the $\mathrm{X}, \mathrm{Y}$ and $\mathrm{Z}$ axes at $10 \mathrm{~Hz}$ frequency. The tri-axial acceleration sensor as shown in Figure 1 was used for the measurement of vibrations at the desired positions.

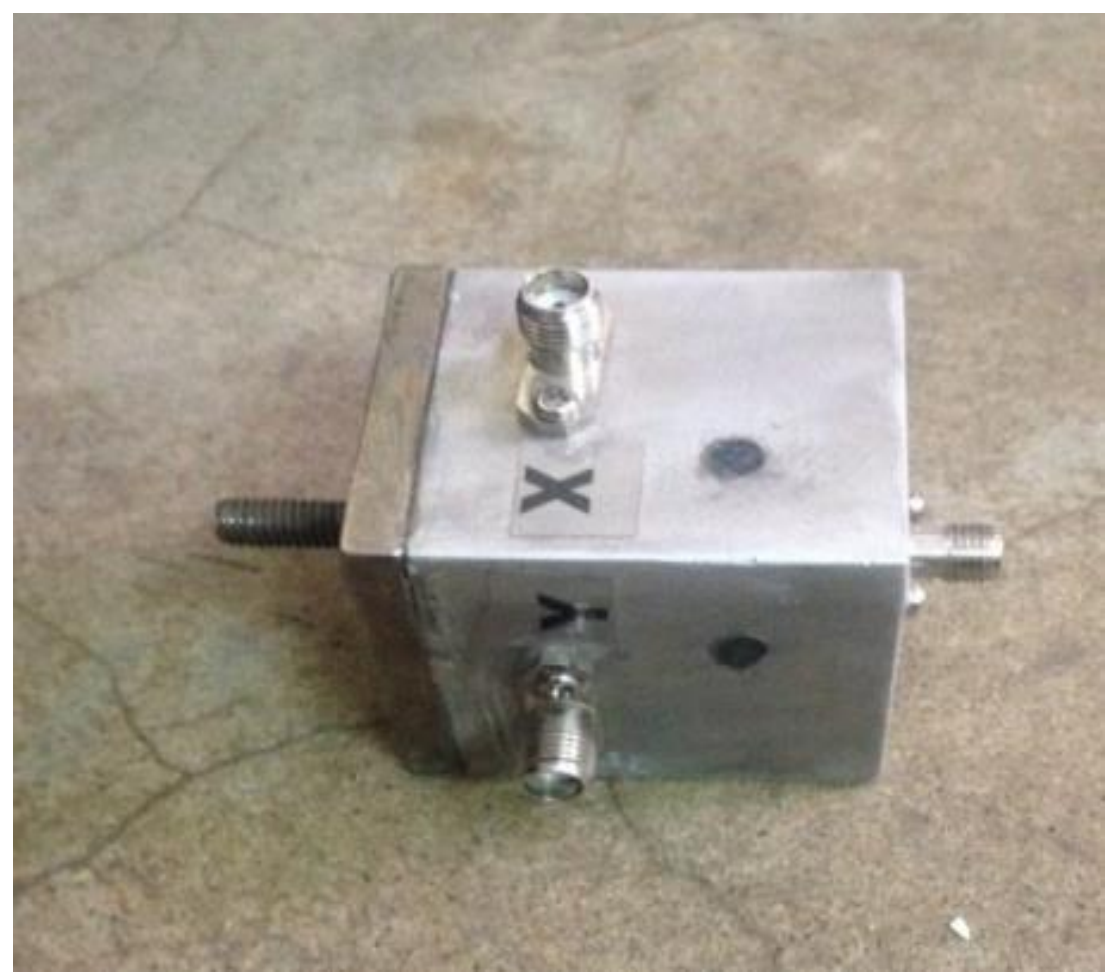

Figure 1. Tri-axial acceleration sensors used for the measurement of vibrations

The tractor was made two run at two constant speeds of $2.30 \mathrm{Km} / \mathrm{hr}$ and $4.20 \mathrm{Km} / \mathrm{hr}$ during both cases and the real time data was recorded separately for each case along horizontal, transverse and vertical directions.

The acceleration sensors used for experimentation were piezoelectric accelerometers, the 
frequency range of 1 to $80 \mathrm{~Hz}$ and sensitive to vibration level of $0.05 \mathrm{~m} / \mathrm{s}^{2}$ capable of measuring vibrations is $5 \mathrm{~m} / \mathrm{s}^{2} \mathrm{RMS}$ with a crest factor as great as three without distortion and with an accuracy of $\pm 0.05 \mathrm{~m} / \mathrm{s}^{2}$.

In this study, acceleration sensor was attached to its own Data Acquisition unit (Figure 2). Sampling rate of DA unit is 800units/second. Function of Data Acquisition unit was to collect data from the acceleration sensor and recorded it into a SD card memory in excel format. Data could be downloaded to the desktop computer installed in the data acquisition system for analysis. Two main functions of data acquisition system are measurement and data logging. The sensor was used to measure output parameters of the tests and the function of data logger is to save the signals of these sensors as time history data. The obtained accelerations were stored in the memory card of data acquisition unit in the form of three excel files configuration. In order to derive the test results, these $\mathrm{X}, \mathrm{Y}$ and $\mathrm{Z}$ axes acceleration time histories can subsequently be transferred to the computer for advance analysis.

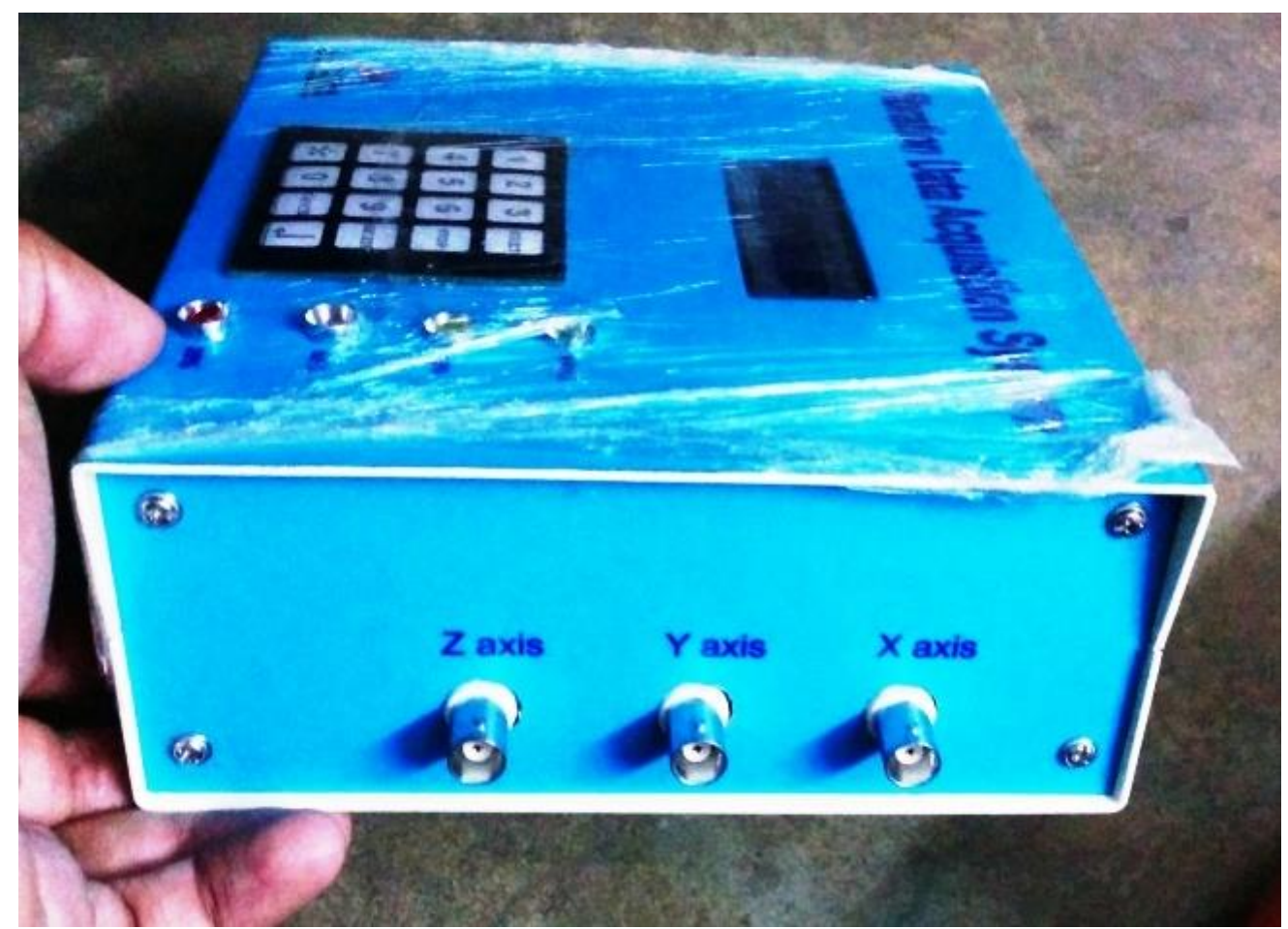

Figure-2. Data Acquisition unit used for the measurement of vibrations

Tri-axial accelerometer was fitted on the seat base of test tractor to measure vibrations transmitted to the seat of tractor (Figure 3). The frequency sensitivity range of an accelerometer was 2-8000 Hz. Every time, acceleration levels were measured simultaneously along three perpendicular directions namely $\mathrm{X}$ longitudinal (pitching), Y transversal/lateral (rolling), and $\mathrm{Z}$ vertical (bouncing/heave) on the base of the tractor seat. 


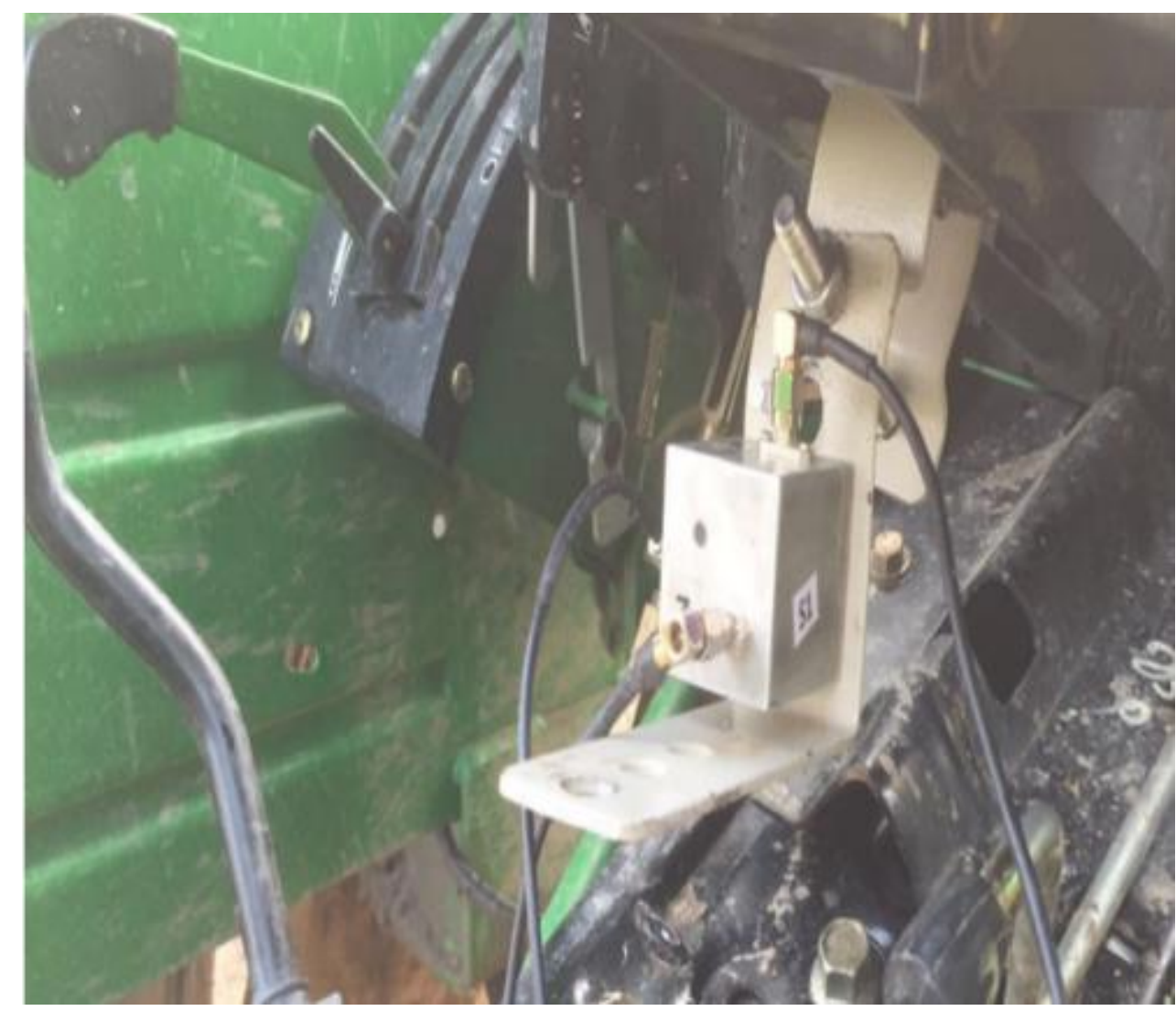

Figure -3. Location of tri-axial accelerometer on the base of tractor seat.

\section{ANALYSIS OF DATA}

\subsection{The Effect of vibration on the tractor's driver seat without implements}

Experiment was conducted on the test tractor without tillage implements. The tri-axial accelerometer was installed at the base of operator's seat. The tractor was made to run at a constant speed of $2.30 \mathrm{Km} / \mathrm{hr}$ and $4.20 \mathrm{Km} / \mathrm{hr}$ and real time data was taken from accelerometer sensor. As it is evident from figure 4 that the magnitude of acceleration in the vertical direction $(\mathrm{z})$ was highest and it was lowest in horizontal direction $(\mathrm{x})$, the transverse (y) direction is in between the vertical direction and horizontal direction. Therefore the tractor seat vibrates maximum in the vertical (z) direction when tractor was moving without implements. It was also observed that with increase in tractor forward speed the measured RMS values of acceleration also increases. 


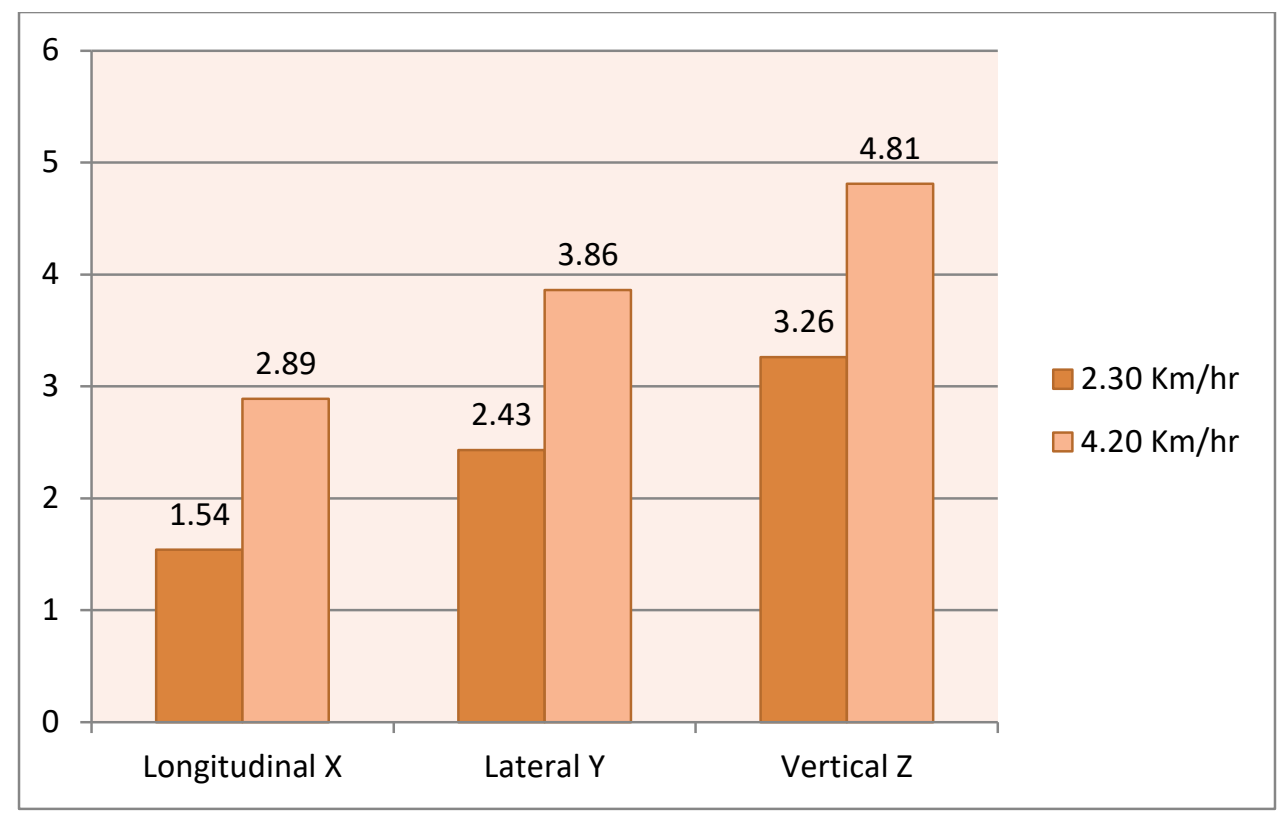

Figure 4. RMS acceleration in all three directions at tractor's seat without implements

\subsection{The Effect of vibration on the tractor's driver seat without implements}

The figure 5 shows the measured acceleration values in horizontal (x), transverse (y) and vertical (z) directions. The forward speed of tractor was kept constant at $2.30 \mathrm{Km} / \mathrm{hr}$ and 4.20 $\mathrm{Km} / \mathrm{hr}$. As the figure shows when tractor was made to work with tillage implements (chisel plough) the measured RMS values of acceleration was highest in transverse (y) direction and lowest in horizontal (x) direction and the vertical (z) direction values lies in between that of lateral (y) direction and longitudinal ( $\mathrm{x}$ ) direction. So it is evident that the tractor seat vibrates maximum in transverse (y) direction. It was also observed that with increase in tractor forward speed the measured RMS values of acceleration also increases.

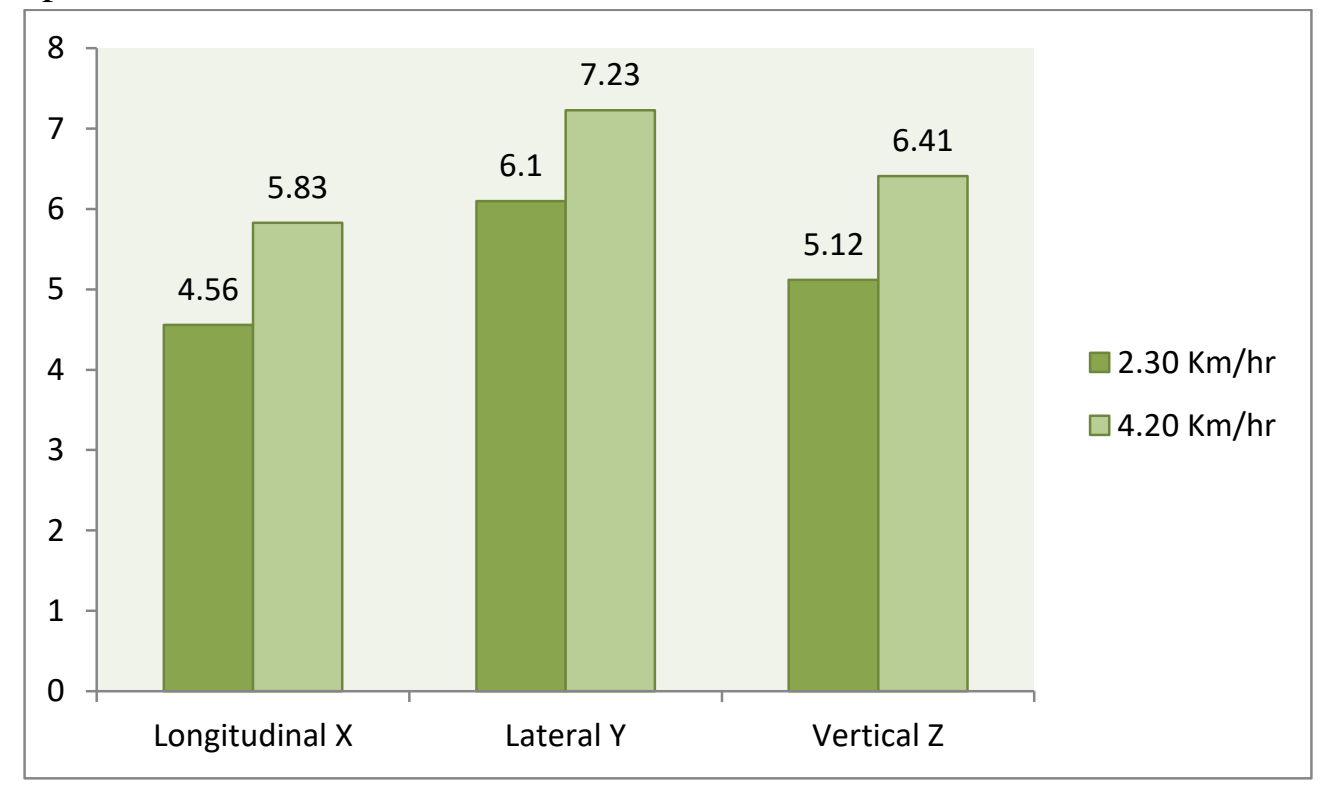

Figure 5. RMS acceleration in all three directions at tractor's seat with implements 
At international levels the effects of vibration on the human have been expressed as criteria for maintaining the efficiency, maintaining the safety limit and comfort range. The ISO-2631 standard is accepted by the ministry of health and medical education and American Conference of governmental industrial hygienists (ACGIH) is used for general body vibrations evaluation. A description of human reaction to vibrations according to ISO-2631 is as given in Table 1 .

Table 1. A detailed expression for effect of vibration on humans (ISO-2631)

\begin{tabular}{l|l} 
Measured vibration, $\mathbf{~} / \mathbf{s}^{2}$ & Level of comfort \\
\hline$<0.315$ & Comfortable \\
\hline $0.315-0.5$ & A little uncomfortable \\
\hline $0.5-1$ & Fairly uncomfortable \\
\hline $1-1.6$ & Uncomfortable \\
\hline $1.6-2.25$ & Very uncomfortable \\
\hline$>2.25$ & Extremely uncomfortable
\end{tabular}

\section{CONCLUSIONS}

The effect of vibrations on tractor driver's seat was investigated with and without tillage implements and it was concluded that

1. The vibrations on seat when tractor was moving without implements the vibration amplitude was highest in vertical direction $\mathrm{Z}$ as compared to transverse direction $\mathrm{Y}$ and horizontal direction $X$. But when the tractor was moving in the fields with tillage implement (chisel plough) the vibration amplitude was high in transverse direction $\mathrm{Y}$ relative to horizontal direction $\mathrm{X}$ and vertical direction $\mathrm{Z}$.

2 The acceleration assessment was evaluated based on international standards (ISO 2631) in both cases and it was observed that when implements for tillage are used, the driver was in an extremely uncomfortable condition.

3 Based on this evaluation, a controller can be designed to control the amplitude of vibrations in operator's seat to reduce to the comfortable levels.

\section{REFRENCES;}

1. Cutini, M., C Bisaglia and E Romano. 2007. Assessment of tractor's tires influence on operator's comfort. Proceedings of XXXII CIOSTAC conference. Nitra, Slovakia, September.

2. Abbdollahpour, S., Zarezadeh, M. R., \& Raoufat, H. (2012). The effect of tire pressure on the vibrations of MF-399 tractor driver's seat. 7th National Congress of Agricultural Machinery Engineering and Mechanization. University of Shiraz, Iran. 
3. Deboli, R., A. Calvo, C. Preti and G. Paletto, 2008. Whole Body Vibration (WBV) transmitted to the operator by tractors equipped with radial tires. International Conference -Innovation Technology to Empower Safety, Health and Welfare in Agriculture and Agro-food Systemsll,Italy

4. Quadros,J. D, Suhas, V and B Shilpa. 2013. Study of vibration and its effects on health of a two wheeler rider. International Journal of Research in Engineering and Technology Volume: 02 Issue: 08 P $51-55$.

5. Holmlund, P., Lundstrom, R., \& Lindberg, L. (2000). Mechanical impedance of the human body in vertical direction. App. Ergon. Vol. 31, pp. 415-422.

6. Hamid, A.A.A, K.A. Mudafer, A.H.A Ahmed and F.F Ali. 2011. Effect of Steering Wheel Vibration on drivers Hands in a Two-Wheel Drivers Hand tractor.Jurnal of Engineering. N6.V17.P 1539-1549. Iraq .

7. Dewangan, K.N., and V.K Tewari. 2008. Characteristics of vibration transmission in the hand arm system and subjective response during field operation of a hand tractor. Biosystem Engineering. volume 100, issue 4, pp 535-546.

8. Scarlett, A. J, J. S Price and R. M. Stayner. 2007. Whole-body vibration: evaluation of emission and exposure levels arising from agricultural tractors. Journal of Terramechanics, v. 44, n. 1, p. 65-73.

9. Mehta, C. A., Shyam, M., Pratap, S., \& Verma, R. N. (2000). Ride vibration on tractor-implement system. App. Ergon. Vol. 31, pp. 323-328.

10. Cvetanovic, B. and D. ZlatkovicL, 2013. Evaluation of whole-body vibration risk in agricultural tractor drivers. Bulg. J. Agric. Sci., 19: 1155-1160.

11. Villibor, Paula, F. Santos, D. Queiroz and D Guedes.2014. Vibration levels on rear and front axles of a tractor in agricultural operations. Acta Scientiarum Technology. v. 36, $n$. $1, p .7-14$.

12. ISO 2631-1-1997: Mechanical variation and Shock - Evaluation of Human Exposure to Whole Body Vibration. Part 1: General Requirements. 